\section{El reformismo entre dos siglos. Historia de la UNL}

\author{
Susana Piazzesi y Natacha Bacolla (2015). Santa \\ Fe, Argentina: Ediciones UNL. 384 páginas. \\ Reseñado por Fernando Manuel Suárez \\ Centro de Estudios Históricos de la Universidad \\ Nacional de Mar del Plata. Argentina CONICET \\ fermsuarez@gmail.com
}

Esta obra que se inscribe dentro de uno de los subgéneros más tradicionales de la disciplina histórica: la historia institucional.

Sin embargo, desde un principio, las autoras logran escapar a los corsés de este tipo de historiografía, sin por ello quitar del centro a su objeto de estudio: la Universidad Nacional del Litoral. Por lo tanto, el trabajo muestra los rasgos propios de una obra conmemorativa institucional, pero esto no va en desmedro de un abordaje profundo, atento a la complejidad de los procesos analizados y sólidamente documentado. El libro se divide en tres extensos capítulos que recorren los diferentes subperíodos de la historia institucional de la UNL y un anexo final referido a cada una de las facultades que conforman dicha casa de estudios. En su primer capítulo, las autoras presentan el germen de la UNL, una universidad de proyección regional con sede en tres provincias. Para analizar este primer tramo de historia toman como eje problemático al "reformismo universitario" e intentan dar cuenta del "espíritu de época" que primaba en esa etapa fundacional. En este primer apartado el foco está puesto justamente en las tensiones entre el ideario reformista y las dificultades para llevarlo a la práctica por un contexto políticamente convulsionado y la propia inestabilidad interna. En el período que va desde 1919 a 1955 las autoras muestran los claroscuros de un proceso de creación y consolidación institucional signado por las banderas reformistas, pero condicionado en su puesta en práctica por numerosos factores político-institucionales.

El segundo apartado refiere a las transformaciones de la UNL a partir de 1955 y hasta el final de la última dictadura. Durante ese período, tal como lo refieren Bacolla y Piazzesi, se produce un relanzamiento de las banderas reformistas - y de cierta radicalización- que impacta fructíferamente en la institución. Sin embargo, en un proceso de alcance nacional, la inestable situación política, signada por experiencias autoritarias, golpeará duramente la autonomía universitaria generando una retracción notoria en muchos de los pilares del proyecto reformista. La intromisión violatoria de la autonomía, incluido el interregno peronista, la persecución y la censura serán los rasgos decisivos durante esos años.

Por último, el tercer apartado narra la etapa contemporánea de la UNL a partir de la reapertura democrática hasta nuestros días. Aquí las autoras enfocan su análisis en la filiación entre la apertura
A 100 años de la Reforma Universitaria de 1918 /

Reseña de libros

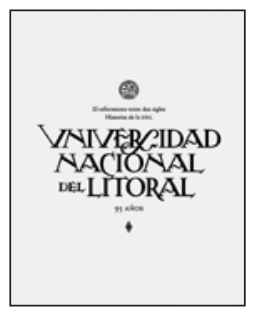

democrática y un nuevo renacer del "reformismo" y sus promesas. En este caso, los obstáculos del proyecto reformista son las restricciones presupuestarias derivadas de las crisis económicas que vivió el país en las décadas del 80 y 990 . En un segundo momento, se analizan las reformas implementadas por la Ley de Educación Superior, las resistencias de los actores institucionales, y el posterior reflujo político-institucional a esas iniciativas ya en el siglo XXI.

En síntesis, el libro de Natacha Bacolla y —póstumo— de Susana Piazzesi logra un sano equilibrio entre una historia institucional típica — da cuenta de las autoridades, de sus cambios estatutarios, de su expansión edilicia, etc. - y una historia política stricto sensu —que analiza la institución en su contexto, los procesos sociopolíticos generales, los conflictos internos a la institución, entre otras cuestiones-. En tal sentido, el trabajo es abundante en datos sobre la institución y demuestra tener un consistente sustento documental: incluye cuadros, tablas, apartados con fragmentos de fuentes de la época y un muy interesante material fotográfico. Una de las principales bazas de El reformismo entre dos siglos... justamente está en la articulación de esa nutrida base de información con un análisis que no rehúye a la problematización ni al planteo de hipótesis. El libro logra, de ese modo, analizar el problema del proyecto de la "universidad reformista" a través de un caso específico y da cuentas de los avances y retrocesos, de los matices y tensiones, de los múltiples elementos que interactúan conflictivamente para dar forma a una institución compleja tal y como es la universidad. 